\title{
The Chironomidae of the Western Carpathian helocrenes: Metacommunity structuring and its drivers in unique habitats
}

\author{
Vanda ŠORFOVÁ, ${ }^{*}$ Vít SYROVÁTKA \\ Department of Botany and Zoology, Faculty of Science, Masaryk University, Kotlářská 2, CZ-611 37 Brno, Czech Republic \\ *Corresponding author: sorfova.vanda@gmail.com
}

\begin{abstract}
Springs are unique and vulnerable habitats, which have always been rather out of focus of the scientist interest. Nevertheless, they frequently host very diverse and species-rich assemblages with high proportion of species more or less adapted to their unique environment and can act as biodiversity hotspots in some areas. The Western Carpathian springs are helocrene springs and represent wide variety of different habitat types, from mineral rich sparsely-vegetated or bryophytes-rich covered helocrenes to acidic peaty sites. Such diversification allows the creation of highly diverse assemblages, in which Chironomidae usually dominate in both species richness and abundance. The aim of this study was to provide a comprehensive overview of chironomid assemblages inhabiting the unique environment of spring fens and factors driving the metacommunity structuring and populations of individual taxa. We examined chironomid assemblages of 62 small, treeless helocrenes sites, which are highly isolated from each other by the terrestrial environment constituting dispersal barriers such as the east-west oriented mountain ridges and valleys. The sampling was performed to cover mesohabitat heterogeneity of study sites. Two main mesohabitats were sampled, the plot with flowing water and coarser substratum near water source (the lotic mesohabitat), and water-logged soil with standing water (the lentic mesohabitat). Study sites hosted nearly 100 chironomid taxa, both mesohabitats were inhabited by chironomid assemblages similar in number of species and abundances and the local environment was proved to be the main driver of compositional changes in chironomid assemblages as expected. Moreover, the significant spatial structure of assemblages was found at the lentic mesohabitat, while biotic interactions described by the abundance of Gammarus fossarum and taxa richness and abundances of predators did not significantly contribute to compositional changes in assemblages at any mesohabitat. Nevertheless, taxa-specific responses revealed populations of many taxa significantly affected by biotic interactions, especially at the more stable lotic mesohabitat, which is in concordance with suggested greater importance of biotic interactions at stable environment. Our results emphasized the importance of multilevel approach in community ecology for proper distinction between different mechanisms of metacommunity structuring. Biotic interaction such as competition can result into the same community patterns as environmental filtering, thus the involvement of detailed analyses of species requirements and interactions is necessary.
\end{abstract}

Key words: Chironomidae; springs; metacommunity structuring; biotic interactions; species responses.

Received: February 2018. Accepted: July 2018.

This paper was presented at the $20^{\text {th }}$ International Symposium on Chironomidae, Trento, Italy, 2-8 July 2017. Session: Ecology and Biomonitoring.

\section{INTRODUCTION}

Spring habitats have been investigated worldwide, however they have always stood aside the main interest of scientists, despite being recognized as important, rare and globally threatened ecosystems providing habitats and the origin of water resources (Meyer et al., 2007; Springer and Stevens, 2009). They include a variable group of sites that can highly differ in the provided environmental conditions and in their invertebrate inhabitants, with Chironomidae usually representing one of the most abundant and species-rich component of spring assemblages (Lindegaard, 1995; Orendt, 2000; Lencioni et al., 2011). An extensive overview of spring research with attention to chironomid species in Europe is given in Lindegaard (1995) with more than 200 taxa known to occur at European cold springs up to 1995. To our knowledge, there appeared 19 studies focusing on community ecology of European springs since then (25 worldwide, Tab. S1), in which chironomids were identified at the lowest possible level (usually genus/species) with the total of more than 380 taxa reported from springs until today (for a complete list of all taxa see Tab. S2). However, as no standardized protocol for spring sampling has been developed yet, the comparison of so far conducted studies is virtually impossible. The studies were focused on different spring types and conducted with different sampling effort and methods. The datasets differ in number of sites, number of plots sampled within one site, time and frequency of 
sampling, types of sampled mesohabitats, sampling device and mesh size used, measured environmental variables, and developmental stage of identified chironomids. Thus, the general overview of taxa richness and abundances of chironomid assemblages inhabiting spring habitats is very hard to compile.

Springs located in the Western Carpathians are of the helocrene type, i.e. upwelling groundwater forms a waterlogged, marshy area with alternating little pools and trickles and hygropetric microhabitats, which is usually drained by a spring brook(s). Such mosaic character provides a wide variety of microhabitats and thus, helocrenes can host very diverse community (Gerecke $e t$ al., 2011). As it may seem that we dealt with only very narrow section of spring habitats, the Western Carpathian helocrenes represent a wide variety of different ecological habitat types that are formed along the gradient of mineral richness, i.e. from acid mineral poor Sphagnum sites to extremely mineral rich calcareous brown-moss sites with tufa formation (Hájek et al., 2006). Such diversity of habitats surely contributed to the total biodiversity of chironomids in the study area and we expected their high taxa richness at the studied sites.

This study aimed to provide an information of taxa richness and abundances of chironomids inhabiting the unique environment of helocrenes and to evaluate the role of factors driving their metacommunity structuring, including the first analysis of biotic interactions. We tested the importance of local environment, spatial structuring and effects of abundance and taxa richness of predators and crustacean Gammarus fossarum Koch, 1836 at levels of chironomid assemblages and populations of individual taxa. The laboratory experiments proved that G. fossarum can feed on animal food, though its predation rate is lower than other gammarids such as Gammarus pulex (Linnaeus, 1758), Gammarus roeselii Gervais, 1835 and Dikerogammarus villosus (Sowinsky, 1894) (Stoffels et al., 2011; Bacela-Spychalska and Velde, 2013). We hypothesized about its significant effect as $G$. fossarum can achieve high population densities resulting into the disturbance effect and/or predation pressure on a chironomid assemblage.

\section{METHODS}

The study sites represented small treeless helocrenes in the Western Carpathians and the target set of 62 nutrient limited sites (Fig. 1) with low productive vegetation was selected based on an extensive botanical research of more than 200 spring fens in the study area (Poulíčková et al., 2005). The study sites are small in size and vegetation is very homogenous within each site, thus the mesohabitat heterogeneity is given by differences in flow conditions. Two main mesohabitats could always be identified: a trickle with flowing water close to the source (the lotic mesohabitat), and shallow pools with standing water (the lentic mesohabitat). Regarding the vulnerability of these small and valuable habitats, one sample from each mesohabitat was taken in the spring and one in the autumn (in years 2006-2012) with the total of four collected samples per site. The samples were quantitative (metal frame of $25 \mathrm{~cm} \times 25 \mathrm{~cm}$, and hand net with $500 \mu \mathrm{m}$ mesh size) and manually sorted and identified in the laboratory.

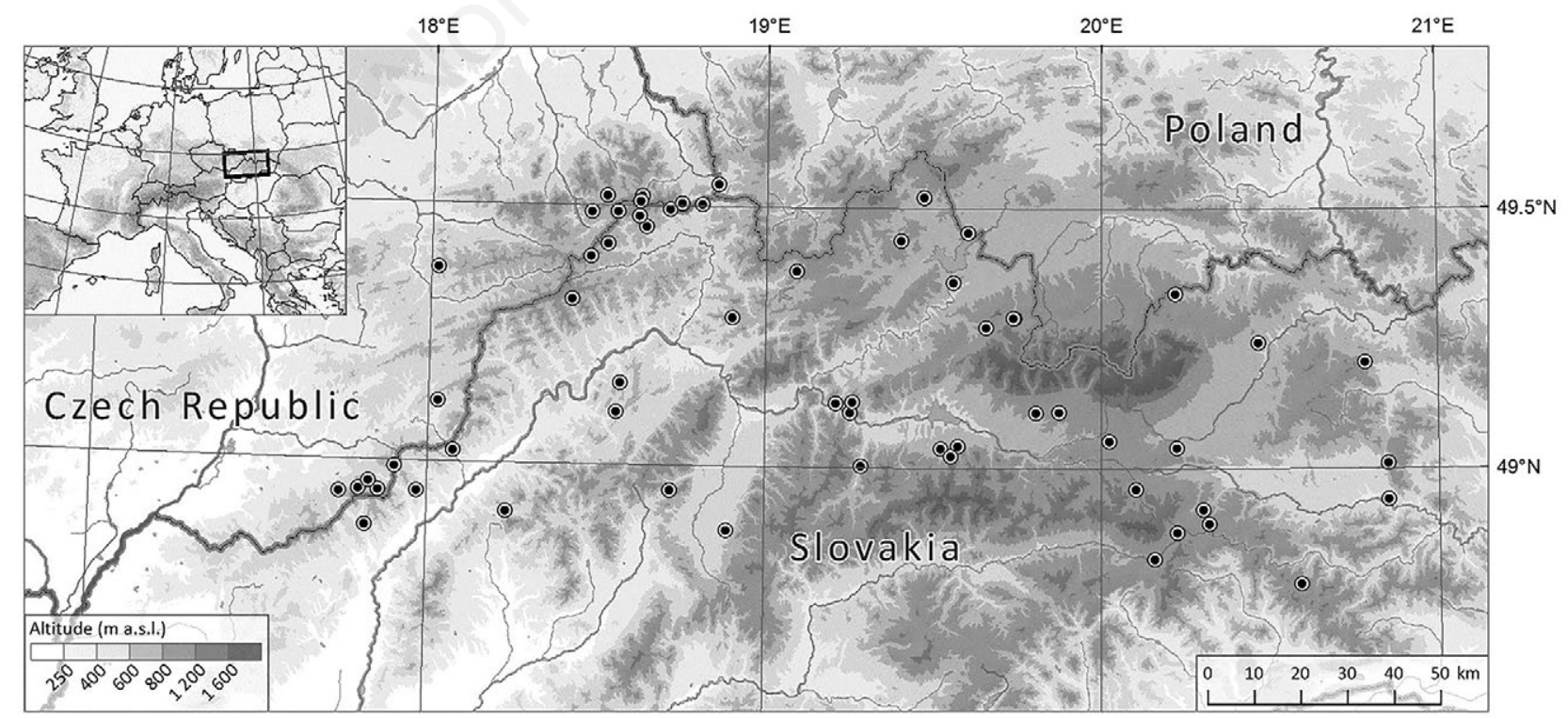

Fig. 1. Map of study sites. 
The sampling was accompanied with the determination of ecologically relevant environmental variables $(\mathrm{pH}$, conductivity, water temperature and discharge, concentration of dissolved oxygen, content of $\mathrm{Ca}^{2+}, \mathrm{Mg}^{2+}$, $\mathrm{Fe}, \mathrm{Al}, \mathrm{NO}_{3}{ }^{-}, \mathrm{NH}_{4}{ }^{+}$and $\mathrm{PO}_{4}{ }^{3-}$ ions) and description of sites (substratum characteristics, vegetation composition Ellenberg's values for moisture and nutrients calculated as unweighted means of all vascular plant species present in a vegetation plot, climatic variables, size and age of sites).

\section{Statistical analyses}

The whole dataset was used for the compilation of a complete taxa list of chironomids inhabiting Western Carpathian helocrenes. For further analyses, a representative subset of 46 sites with known age and size of spring area was selected (for further details of evaluation of the age of sites see Horsák et al., 2015). Samples from spring and autumn were summed up and mesohabitats were kept separately. Environmental variables with skewed distribution were transformed prior to analyses (see Tab. S3 for used transformation). The relationships among variables were described by Spearman's correlation coefficients and 13 representative variables with the lowest intercorrelations were selected (Tab. S3). Multiscale distance relationships among sites were described by spatial variables obtained by distance-based Moran's eigenvector maps (dbMEMs, Dray et al., 2006) and only dbMEMs with positive eigenvalues expressing positive spatial correlation were considered. Biotic interactions were represented by the abundance of G. fossarum and the species richness and abundance of predators. All abundances were logarithmically transformed.

Differences in the patterns in taxa composition at different mesohabitats were evaluated by Non-Metric Multidimensional Scaling (NMDS; Cox and Cox, 2001) on Bray-Curtis distances. The patterns were interpreted by environmental variables significantly fitted into the NMDS diagrams.

Three explanatory models using distance-based RDA (dbRDA; Legendre and Anderson, 1999) were constructed for assemblages of both mesohabitats, an environmental model, a spatial model and a model with biotic interactions. Variables entering each model were selected by forward selection (Blanchet et al., 2008). Linear trends were tested using geographical coordinates as explanatory variables in the dbRDA. If at least two models were significant, the total variance was partitioned into the pure fractions explained by individual models, the fractions of variability shared by two or all models and the unexplained variability. The explained variance was expressed as an adjusted $\mathrm{R}^{2}$ (PeresNeto et al., 2006) and significances were tested by the 9999-permutation procedure.

The environmental, spatial and biotic predictors found to significantly influenced assemblage's composition at mesohabitats were further analysed to identify individual taxa responses, which determine the response of the assemblages. These responses were evaluated using generalized linear models (GLM; McCullagh and Nelder, 1989). Only taxa occurring at five and more sites and found in at least 20 individuals were analysed. Poisson distribution of errors with correction for over-dispersion (quasi-Poisson distribution) was used in models and the proportion of explained variability was expressed as McFadden's pseudo R ${ }^{2}$ (McFadden, 1974). All analyses were performed in R software (R Core Team, 2017) using "vegan" (Oksanen et al., 2018), "packfor" (Dray et al., 2011) and "PCNM" (Legendre et al., 2012) packages.

\section{RESULTS}

The chironomid assemblages of 62 helocrenes were formed by 27,764 individuals belonging to 95 taxa (for all taxa found at the Western Carpathian helocrenes see Tab. S2). The most taxa-rich subfamily was Orthocladiinae with 60 taxa, followed by Chironominae (19), Tanypodinae (12) and Diamesinae and Prodiamesinae (both 2 taxa). Regarding abundances, the three most diverse subfamilies were nearly equally abundant at our sites. The taxa richness and abundance of chironomids were similar at both mesohabitats. Two thirds of taxa inhabited both mesohabitats (68), the lotic mesohabitat was exclusively inhabited by 10 taxa (e.g. Chaetocladius perennis (Meigen, 1830), Diplocladius cultriger Kieffer, 1908, Epoicocladius ephemerae (Kieffer, 1924)) and 17 taxa were found only in the lentic mesohabitat (e.g. Odontomesa fulva (Kieffer, 1919), Acricotopus lucens (Zetterstedt, 1850), Cricotopus gr. sylvestris). The quantitative samples of 46 helocrenes captured 67 taxa at the lotic mesohabitat and 76 taxa at the lentic one, which means loss of 11 and 9 taxa, respectively, compared to the whole dataset. The criteria for individual evaluation of taxa responses met 34 taxa, 32 at the lotic mesohabitat (Tab. 1) and 28 at the lentic mesohabitat (Tab. 2).

The lotic mesohabitat was better oxygenated, with lower water temperature, higher proportion of inorganic substratum and lower amount of coarse particulate organic matter (CPOM). However, none differences were found to be significant. The amount of CPOM together with area of sites, Ellenberg's value of moisture and average air temperature in January significantly explained the spatial configuration of both lotic and lentic mesohabitats in the NMDS diagrams (Fig. 2). Altogether, nine environmental variables were significantly fitted into the NMDS diagram of lotic sites. Besides the above-mentioned variables, the dissolved oxygen, the content of bivalent ions and age of sites were the most important. In contrast, the Ellenberg's value of nutrients was the only significantly fitted 
additional variable at the lentic mesohabitat. Using forward selection, seven and four environmental predictors were identified as the most important for lotic and lentic assemblages, respectively (Fig. 3). Three variables, the dissolved oxygen, the content of bivalent ions and CPOM, were identified as significant at both mesohabitats. Variation decomposition and individual taxa responses confirmed the prevalent role of local environment for chironomid assemblages at the lotic mesohabitat (Fig. 3 and Tab. 1). Taxa populations mostly reflected moisture, the mineral richness of water, CPOM and discharge. In comparison, only half of taxa showed significant response to at least one of the environmental predictors at the lentic mesohabitat with the average annual air temperature in January and the mineral richness water being the mostly followed (Tab. 2).

Tab. 1. Results of GLM models on abundance data at the lotic mesohabitat. Significant responses of taxa to predictors selected by forward selection to be important for assemblage's composition are displayed in columns. The responses are determined as marginal effects and McFadden's PseudoR ${ }^{2}$ as a measure of explained variability. They are denoted by + (positive) and $-($ negative) signs and displayed in brackets and significance $\mathrm{P}<0.01$ is given in bold.

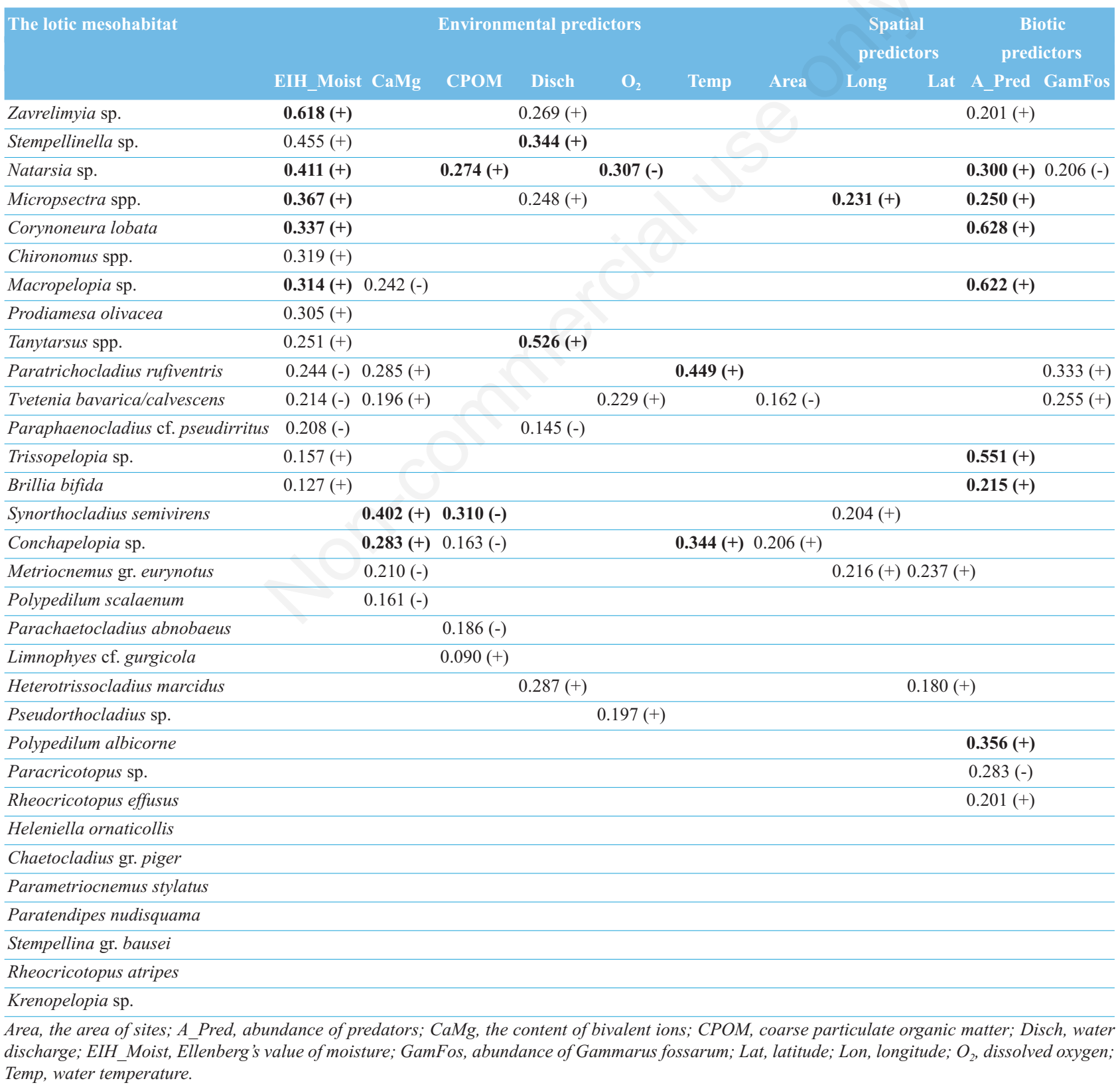


In contrast to the lotic assemblages, we found the significant spatial structure of the lentic ones, although significant only at the broadest spatial scale represented by latitude and longitude (Fig. 3). Eight taxa with significant link to latitude and longitude were identified, six of them without any relationship with the local environment (Tab. 2). In comparison, there were only four taxa with significant response to spatial predictors at the lotic mesohabitat and all of them were significantly driven also by some environmental predictor (Tab. 1).

According to the variance partitioning, biotic interactions had low and insignificant impact on assemblage's composition at both mesohabitats (Fig. 3).
Nevertheless, there were 12 and five taxa at the lotic and lentic mesohabitat, respectively, with significant responses to the biotic predictors (Tabs. 1 and 2). Taxa responded mainly to the abundance of predators, while contrary to our expectations populations seemed to be unaffected by $G$. fossarum.

\section{DISCUSSION}

Helocrene springs in the Western Carpathians host very diverse and abundant assemblages of chironomid species. The taxa richness found at our study sites is comparable to the number of chironomid taxa found in

Tab. 2. Results of GLM models on abundance data at the lentic mesohabitat. Significant responses of taxa to predictors selected by forward selection to be important for assemblage's composition are displayed in columns. The responses are determined as marginal effects and McFadden's PseudoR ${ }^{2}$ as a measure of explained variability. They are denoted by $+($ positive) and $-($ negative) signs and displayed in brackets and significance $\mathrm{P}<0.01$ is given in bold.

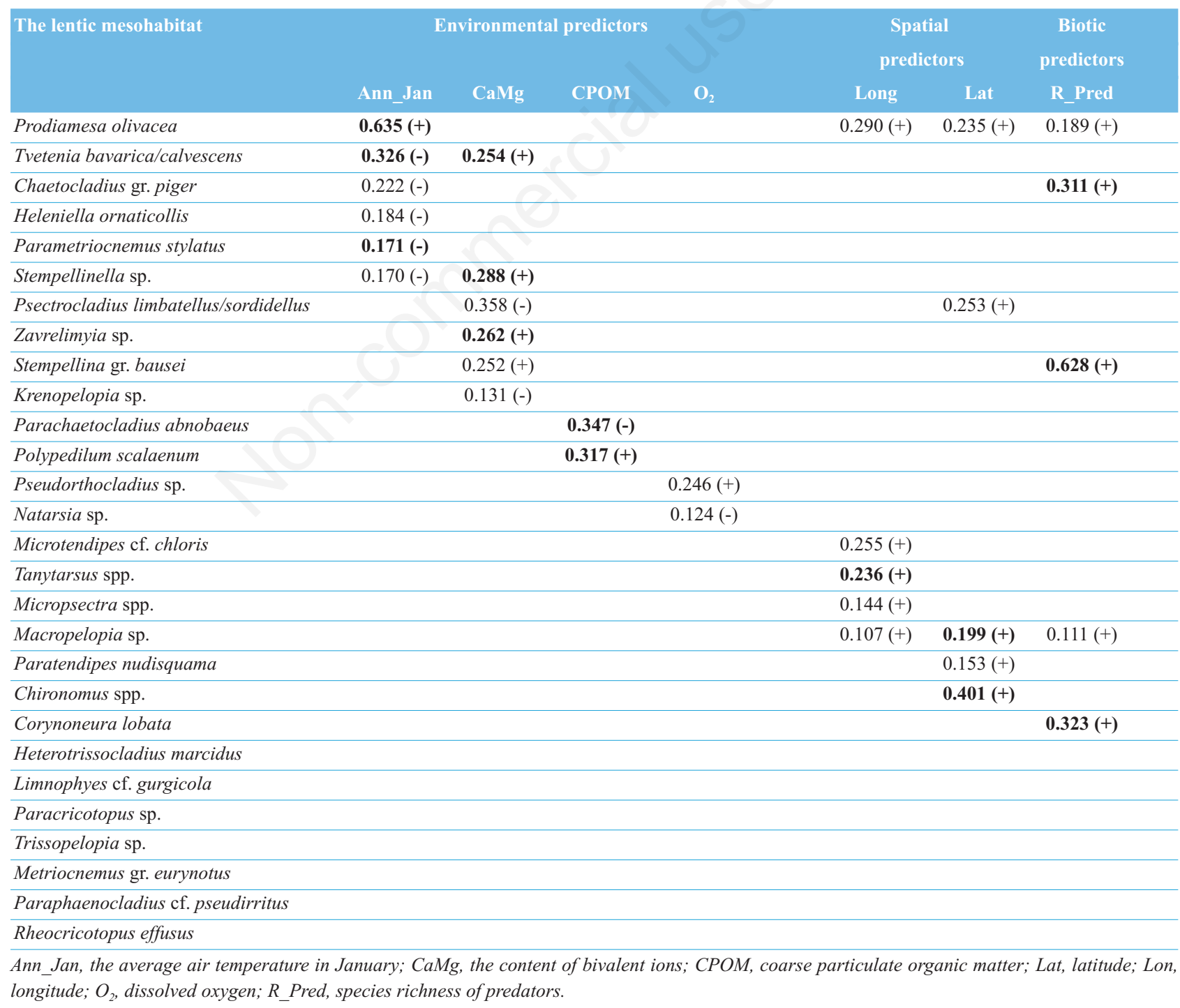


Alpine springs (Marziali et al., 2009; Lencioni et al., 2011, 2012) and boreal springs (Ilmonen et al., 2009; Virtanen et al., 2009). Nevertheless, these studies provided data from various spring types and the number of sites was usually considerably higher, from 81 to 153 sites, which proves that the Western Carpathian helocrenes are important habitats in terms of chironomid diversity. Studies on the helocrene type itself are very

Lotic mesohabitat
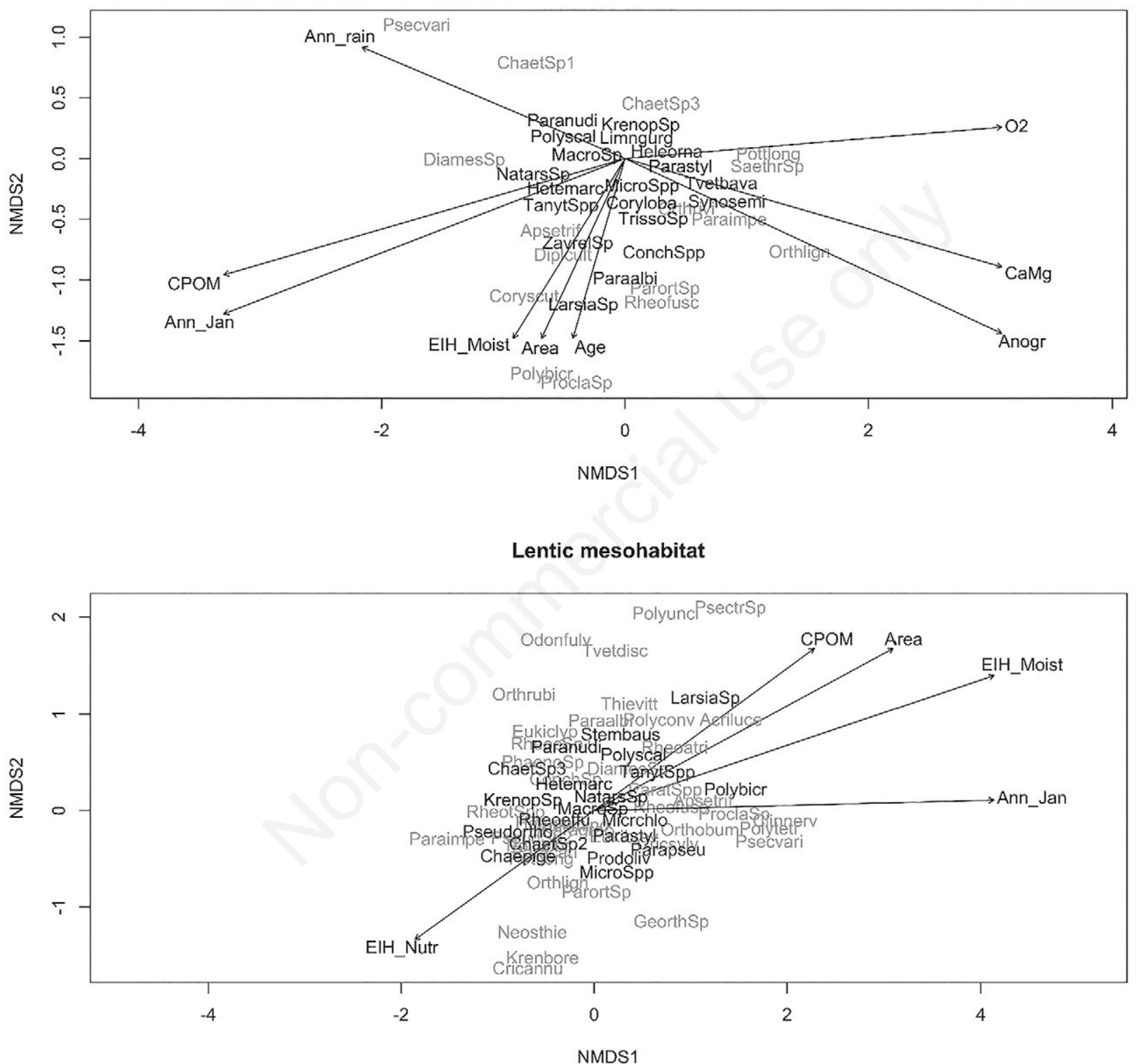

Fig. 2. Spatial configuration of sites in NMDS diagrams for lotic and lentic mesohabitats. Only significantly fitted taxa and variables are displayed. Taxa with abundance $<250$ individuals are given in grey, taxa with abundance $>250$ individuals are given in black. For taxa abbreviation see Tab. S2. Environmental variables fitted into the diagram of the lotic sites: the age of sites $\left(\mathrm{Age}, \mathrm{R}^{2}=0.24, \mathrm{P}=0.002\right)$, the average annual temperature in January (Ann_Jan, $\left.\mathrm{R}^{2}=0.20, \mathrm{P}=0.007\right)$, the average annual precipitation $\left(\right.$ Ann_rain, $\left.\mathrm{R}^{2}=0.17, \mathrm{P}=0.025\right)$, the inorganic substratum (Anogr, $\mathrm{R}^{2}=0.18, \mathrm{P}=0.011$ ), the area of sites (Area, $\mathrm{R}^{2}=0.35, \mathrm{P}=0.001$ ), the content of bivalent ions $(\mathrm{CaMg}$, $\left.\mathrm{R}^{2}=0.20, \mathrm{P}=0.008\right)$, coarse particulate organic matter $\left(\mathrm{CPOM}, \mathrm{R}^{2}=0.24, \mathrm{P}=0.005\right)$, Ellenberg's value of moisture (EIH Moist, $\mathrm{R}^{2}=0.27$, $\mathrm{P}=0.004)$, the dissolved oxygen $\left(\mathrm{O} 2, \mathrm{R}^{2}=0.31, \mathrm{P}=0.001\right)$. Environmental variables fitted into the diagram of the lentic sites: the average annual temperature in January (Ann_Jan, $\mathrm{R}^{2}=0.22, \mathrm{P}=0.006$ ), the area of sites (Area, $\mathrm{R}^{2}=0.20, \mathrm{P}=0.013$ ), Ellenberg's value of moisture (EIH_Moist, $\mathrm{R}^{2}=0.22, \mathrm{P}=0.008$ ), Ellenberg's value of nutrients (EIH_Nutr, $\left.\mathrm{R}^{2}=0.17, \mathrm{P}=0.021\right)$, coarse particulate organic matter (CPOM, $\mathrm{R}^{2}=0.27, \mathrm{P}=0.003$ ). 
rare and therefore the possibility of comparison is limited. The study of Bolton (1992) focused on one helocrene spring and found 96 chironomid taxa. However, different mesohabitats were sampled and all developmental stages of Chironomidae were collected. The study of Anderson and Anderson (1995) investigated chironomid fauna at six helocrenes using emergence traps and collected 28 taxa. Unlike these American helocrenes or many helocrenes in boreal zone (Salmela, 2004; Ilmonen et al., 2009), the Western Carpathian fens are very small (usually $0.1-1$ ha) and highly fragmented. The environmental heterogeneity necessary for such high diversity found at our study sites is achieved rather by a wide variety of ecological types of fens present in the study area than a heterogeneity of individual fens, although the typical mosaic character of helocrenes is evident even at small-sized sites.

\section{The local environment}

As expected, the local environmental conditions predicted the composition of chironomid assemblages best at both mesohabitats. The leading role of the local environment in metacommunity structuring in headwaters was repeatedly confirmed by numerous studies (Brown and Swan, 2010; Landeiro et al., 2012; Rádková et al., 2014). The chironomid assemblages at both mesohabitats were affected by the amount of CPOM, mineral richness of water, dissolved oxygen and soil moisture content. The effects of substratum and the gradient of mineral richness are necessarily interconnected to some extent and determine the environment of studied helocrenes, form microhabitat heterogeneity and provide shelters and food resources for organisms (Fumetti et al., 2006; Ilmonen et al., 2009; Lencioni et al., 2011). In general, vegetation composition, microbial activity, decomposition rate and accumulation of organic matter and special microhabitats such as tufa formations are all dependent on $\mathrm{pH}$ and the availability of ions and nutrients at studied helocrenes (Hájek et al., 2006; Rádková et al., 2017).

Oxygen content is one of the key factors driving distribution of chironomids (Rossaro et al., 2007; Moller Pillot, 2009). Taxa inhabiting springs are usually cold stenothermal and low oxygen intolerant taxa (Orthocladiinae, e.g. Brillia bifida (Kieffer, 1909), Corynoneura lobata Edwards, 1924, Synorthocladius semivirens (Kieffer, 1909)) and stenooxybiont taxa (Tanytarsini, e.g. Micropsectra spp., Stempellina sp., Stempelinella sp.). These taxa do not possess adaptions such as the presence of haemoglobin, developed ventral tubules and respiratory thoracic horn in pupal stage and the way they can treat temporary lack of oxygen is their ability to switch from aerobic to anaerobic metabolism by glycogenolysis (Vallenduuk and Moller Pillot, 2007). But as majority of spring-fen taxa have small larvae with higher metabolic rate and the glycogenolysis is dependent on glycogen supply, they are less resistant to anoxia than larger species. Nevertheless, if the oxygen supply is sufficient, they can tolerate higher water temperature and water level fluctuations that can influenced assemblages especially at the lentic mesohabitat.

Ellenberg's value of moisture mostly reflects average lowest moisture content in summer and correlates also with the average annual groundwater level (Diekmann, 2003). It increased with the area of sites and most taxa showed positive linkage with moisture (e.g. Stempelinella sp., Macropelopia sp., C. lobata). To maintain higher soil moisture and groundwater level, the stable and sufficient water source is needed. The stronger water seepage, the larger waterlogged area may be created. As small
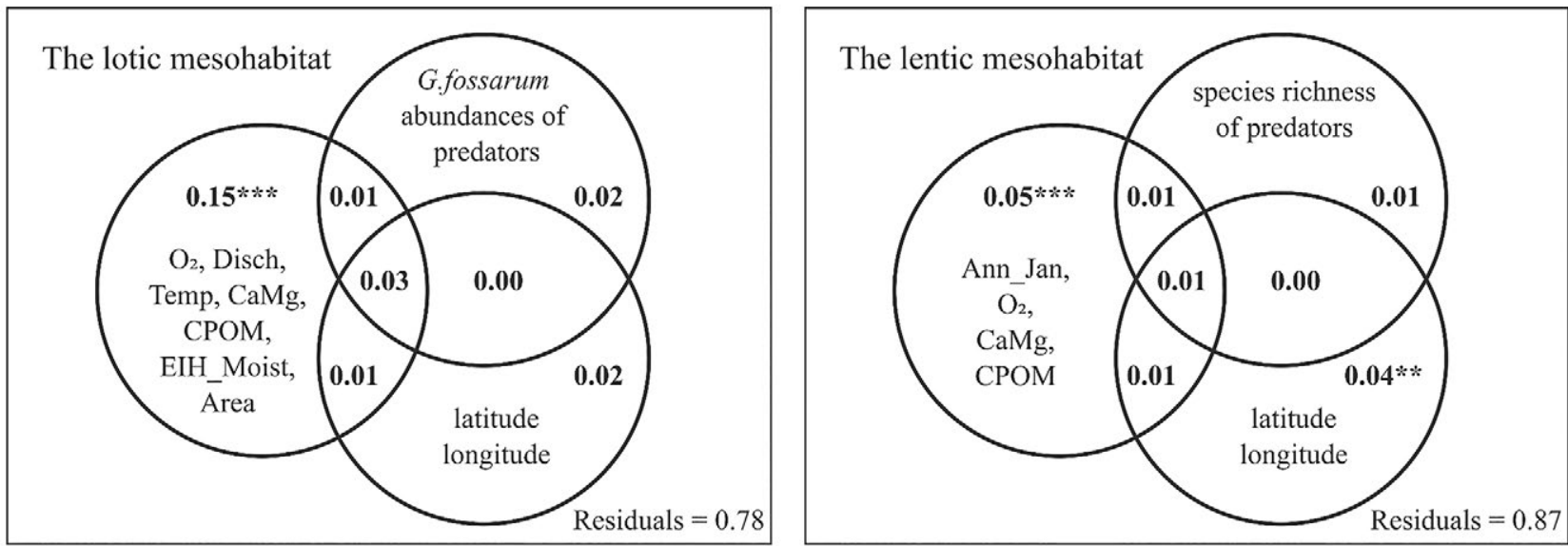

Fig. 3. Variance partitioning for both mesohabitats. The significant fractions of variability are marked with asterisks and predictors significantly contributed to the explained variability by individual models (environmental, spatial, biotic) are listed in the corresponding circle. 
helocrenes may be prone to partial desiccation during summer period, the soil moisture and area of sites can also represent a proxy for a stability of sites and their persistence in time (Horsák et al., 2015). On the other hand, the partial desiccation and fluctuation of environmental conditions can be restricted mostly to the waterlogged area in the spring source surrounding, i.e. the lentic mesohabitat, while the proximity of water source may guarantee more or less stable water and temperature regime at the lotic mesohabitat (Glazier, 1991; Cantonati et al., 2006). The stability of the mesohabitat characteristics may thus be one of the causes of higher predictive power of the environmental filtering of chironomid taxa and assemblage's composition at the lotic mesohabitat.

\section{The spatial structure of assemblages}

In contrast to the lotic assemblages determined predominantly by the local environment, the lentic assemblages showed significant spatial structure. The absence of spatial structure in the lotic assemblages suggested that dispersal abilities of taxa did not limit the colonisation of study sites, despite the presence of dispersal barriers in the study area (Rádková et al., 2014). Although the significance of the spatial structure may be a coincidence, the explained variability is not negligible and nearly one third of taxa exhibited significant spatial structure of their populations at the lentic mesohabitat. The spatial structure can be considered as an evidence for various processes that have generated it, even those that cannot be directly measured, e.g. predation, competition, human impact, disturbances, historical events, etc. (Borcard et al., 1992; Borcard and Legendre, 1994). Thus, the significance may be given by some environmental, geographical or climatic variables, which were not evaluated, e.g. the food supply and its quality. The taxa with spatially structured populations prefer rather lentic and/or pool habitats without direct water flow (e.g. Paratendipes nudisquama (Edwards, 1929), Macropelopia sp., Microtendipes cf. chloris, Chironomus sp.) and they feed mainly on fine particulate organic matter (FPOM) and detritus (Moller Pillot, 2009). The quantity and quality of detritus is determined by vegetation composition (Raich and Tufekcioglu, 2000), which highly depends on the mineral richness of water and other properties of different ecological types of helocrenes and may significantly differ among sites in the study area (Hájek et al., 2006; Rádková et al., 2017).

\section{The importance of biotic interactions}

One of the often-repeated statements is that the biotic interactions are supposed to be more important in stable environments (Minshall, 1968; Townsend and Hildrew,
1994). However, the biotic component had only minor and insignificant influence on assemblage's composition at both mesohabitats. One of the possible explanations is that the studied helocrenes are not as stable as springs are expected to be. Unlike karstic coldwater rheocrenes in Croatia (Ivković et al., 2015) and the Alps (Gerecke et al., 2011) study sites do exhibit a significant daily and seasonal fluctuation of water temperature, as well as changes in the water level caused by melting snow in the spring, drying out in the summer or heavy rains causing floods (Gerecke et al., 2011). Moreover, the studied helocrenes represented highly variable set of habitat types forming strong environmental gradients and the importance of biotic interactions then can be masked by the environmental heterogeneity. On the other hand, populations of many taxa did show significant responses to biotic predictors, especially at the more stable lotic mesohabitat, which would be in concordance with the original statement. The latest research highlighted the dependence of environment and species interactions. Competition among species can lead to patterns identical to those resulting from environmental filtering and our ability to accurately infer environmental filtering may be questionable (Cadotte and Tucker, 2017a, 2017b). Thus, more specific analyses including e.g. classification of predators and their prey according to the body size and life traits, mutual exclusion of species, competition among species etc. will reveal essential information on the role of biotic and environmental predictors in structuring metacommunities of spring-fen fauna.

\section{CONCLUSIONS}

Our results demonstrated that the Western Carpathian helocrenes are important habitats for chironomids. The wide variety of different ecological types in combination with mesohabitat heterogeneity and within-site mosaic character provide environment for highly taxa-rich, diverse and abundant assemblages. The local environment was the main driver of assemblage's composition, but our results showed that the multilevel approach and detailed analyses of species requirements and interspecies interactions are necessary for proper understanding the roles of different mechanisms in metacommunity structuring, especially for a proper distinction between the effects of the local environment and biotic interactions.

\section{ACKNOWLEDGMENTS}

We thank Ondřej Hájek for the map preparation. This research was financially supported by the Czech Science Foundation (GA16-03881S). 


\section{REFERENCES}

Anderson TM, Anderson NH, 1995. The insect fauna of spring habitats in semiarid rangelands in central Oregon. J. Kansas Entomol. Soc. 68/2:65-76.

Bacela-Spychalska K, van der Velde G, 2013. There is more than one "killer shrimp": trophic positions and predatory abilities of invasive amphipods of Ponto-Caspian origin. Freshwater Biol. 58:730-741.

Blanchet FG, Legendre P, Borcard D, 2008. Forward selection of explanatory variables. Ecology 89/9:2623-2632.

Bolton MJ, 1992. Chironomidae (Diptera) of Cedar Bog, Champaign County, Ohio. Ohio J. Sci. 92:147-152.

Borcard D, Legendre P, Drapeau P, 1992. Partialling out the spatial component of ecological variation. Ecology 73:1045-1055.

Borcard D, Legendre P, 1994. Environmental control and spatial structure in ecological communities: an example using oribatid mites (Acari, Oribatei). Environ. Ecol. Stat. 1:37-61.

Brown BL, Swan CM, 2010. Dendritic network structure constrains metacommunity properties in riverine ecosystems. J. Anim. Ecol. 79:571-580.

Cadotte MW, Tucker CM, 2017a. Should environmental filtering be abandoned? Trends Ecol. Evol. 32:429-437.

Cadotte MW, Tucker CM, 2017b. Embracing the nonindependence of the environmental filter: A reply to responses. Trends Ecol. Evol. 32:886-887.

Cantonati M, Gerecke R, Bertuzzi E, 2006. Springs of the Alps sensitive ecosystems to environmental change: from biodiversity assessments to long-term studies. Hydrobiologia 562:59-96.

Cox TF, Cox MAA, 2001. Multidimensional scaling. Chapman and Hall: 328 pp.

Diekmann M, 2003. Species indicator values as an important tool in applied plant ecology - a review. Basic Appl. Ecol. 4:493-506.

Dray S, Legendre P, Peres-Neto PR, 2006. Spatial modelling: a comprehensive framework for principal coordinate analysis of neighbour matrices (PCNM). Ecol. Model. 196:483-493.

Dray S, Legendre P, Blanchet G, 2011. packfor: Forward selection with permutation (Canoco p. 46). R package version 0.0-8. https://r-forge.r-project.org/R/?group_id=195

Gerecke R, Cantonati M, Spitale D, Stur E, Wiedenbrug S, 2011. The challenges of long-term ecological research in springs in the northern and southern Alps: indicator groups, habitat diversity, and medium-term change. J. Limnol. 70:168-187.

Glazier DS, 1991. The fauna of North American temperate cold springs: patterns and hypotheses. Freshwater Biol. 26:527-542.

Hájek M, Horsák M, Hájková P, Dítě D, 2006. Habitat diversity of central European fens in relation to environmental gradients and an effort to standardise fen terminology in ecological studies. Perspect. Plant Ecol. Evol. Syst. 8:97-114.

Horsák M, Rádková V, Syrovátka V, Bojková J, Křoupalová V, Schenková J, Zajacová J, 2015. Drivers of aquatic macroinvertebrate richness in spring fens in relation to habitat specialization and dispersal mode. J. Biogeogr. 42:2112-2121.

Ilmonen J, Paasivirta L, Virtanen R, Muotka T, 2009. Regional and local drivers of macroinvertebrate assemblages in boreal springs. J. Biogeogr. 36:822-834.

Ivković M, Miliša M, Baranov V, Mihaljević Z, 2015. Environmental drivers of biotic traits and phenology patterns of Diptera assemblages in karst springs: The role of canopy uncovered. Limnologica 54:44-57.

Landeiro VL, Bini LM, Melo AS, Pes AMO, Magnusson WE, 2012. The role of dispersal limitation and environmental conditions in controlling caddisfly (Trichoptera) assemblages. Freshwater Biol. 57:1554-1564.

Legendre P, Borcard D, Blanchet FG, Draz S, 2012. PCNM: MEM spatial eigenfunction and principal coordinate analyses. $\mathrm{R}$ package version 2.1-2. https://r-forge.rproject.org/R/?group_id=195

Legendre P, Anderson MJ, 1999. Distance-based redundancy analysis: Testing multispecies responses in multifactorial ecological experiments. Ecol. Monogr. 69:1-24.

Lencioni V, Marziali M, Rossaro B, 2011. Diversity and distribution of chironomids (Diptera, Chironomidae) in pristine Alpine and pre-Alpine springs (Northern Italy). J. Limnol. 70:106-121.

Lencioni V, Marziali L, Rossaro B, 2012. Chironomids as bioindicators of environmental quality in mountain springs. Freshw. Sci. 31:525-541.

Lindegaard C, 1995. Chironomidae (Diptera) of European cold springs and factors influencing their distribution. J. Kansas Entomol. Soc. 38:108-131.

Marziali L, Lencioni V, Rossaro B, 2009. The chironomids (Diptera: Chironomidae) from 108 Italian Alpine springs. Verh. Internat. Verein. Limnol. 30:1-3.

McCullagh P, Nelder JA, 1989. Generalized linear models, $2^{\text {nd }}$ edition London. Chapman and Hall.

McFadden D, 1974. Conditional logit analysis of quantitative choice behaviour, p. 105-142. In: P. Zarembka (ed.), Frontiers in econometrics. Academic Press, New York.

Meyer JL, Strayer DL, Wallace JB, Eggert SL, Helfman GS, Leonard NE, 2007. The contribution of headwater streams to biodiversity in river networks. J. Am. Water Resour. As. 43:86-103.

Minshall GW, 1968. Community dynamics of the benthic fauna in a woodland springbrook. Hydrobiologia 32:305-339.

Moller Pillot HKM, 2009. Chironomidae larvae of the Netherlands and adjacent lowlands: Biology and ecology of the Chironomini. KNNV Publishing, Zeist: 270 pp.

Oksanen J, Blanchet FG, Friendly M, Kindt R, Legendre P, McGlinn D, Minchin PR, O'Hara RB, Simpson GL, Solymos P, Henry M, Stevens H, Szoecs E, Wagner H, 2018 vegan: Community ecology package. R package version 2.4-6. https://cran.r-project.org/web/packages/ vegan/index.html

Orendt C, 2000. The chironomid communities of woodland springs and spring brooks, severely endangered and impacted ecosystems in a lowland region of eastern Germany (Diptera: Chironomidae). J. Insect Conserv. 4:79-91.

Peres-Neto PR, Legendre P, Dray S, Borcard D, 2006. Variation partitioning of species data matrices: Estimation and comparison fractions. Ecology 87:2614-2625.

Poulíčková A, Hájek M, Rybníček K, 2005. Ecology and palaeoecology of spring fens in the western part of the Carpathians. Palacký University, Olomouc. 
R Core Team, 2017. R: a language and environment for statistical computing. R Foundation for Statistical Computing, Vienna. Available at: http://www.R-project. org.

Rádková V, Bojková J, Křoupalová V, Schenková J, Syrovátka V, Horsák M, 2014. The role of dispersal mode and habitat specialisation in metacommunity structuring of aquatic macroinvertebrates in isolated spring fens. Freshwater Biol. 59:2256-2267.

Rádková V, Polášková V, Bojková J, Syrovátka V, Horsák M, 2017. Environmental filtering of aquatic insects in spring fens: patterns of species-specific responses related to specialist-generalist categorization. Hydrobiologia 797: 159-170.

Raich J, Tufekcioglu A, 2000. Vegetation and soil respiration: correlations and controls. Biogeochemistry 48:71-90.

Rossaro B, Solimini A, Lencioni V, Marziali L, Giacchini R, Parenti P, 2007. The relationship between body size, pupal thoracic horn development and dissolved oxygen in Chironomini (Diptera: Chironomidae). Fund. Appl. Limnol. - Arch. Hydrobiol. 169:331-339.

Salmela J, 2004. Semiaquatic flies (Diptera, Nematocera) of three mires in the southern boreal zone, Finland. Memoranda Soc. Fauna Flora Fennica 80:1-10.

Springer AE, Stevens LE, 2009. Spheres of discharge of springs. Hydrogeol. J. 17:83-93.

Stoffels BEMW, Tummers JS, van der Velde G, Platvoet D, Hendriks HWM, Leuven RSEW, 2011. Assessment of predatory ability of native and non-native freshwater gammaridean species: A rapid test with water flea as prey. Curr. Zool. 57:836-843.

Townsend CR, Hildrew AG, 1994. Species traits in relation to a habitat templet for river systems. Freshwater Biol. 31:265-275.

Vallenduuk HJ, Moller Pillot HKM, 2007. Chironomidae larvae: General ecology and Tanypodinae. KNNV Publishing, Zeist: $172 \mathrm{pp}$.

Virtanen R, Ilmonen J, Paasivirta L, Muotka T, 2009. Community concordance between bryophyte and insect assemblages in boreal springs: a broad-scale study in isolated habitats. Freshwater Biol. 54:1651-1662.

von Fumetti S, Nagel P, Scheifhacken N, Baltes B, 2006. Factors governing macrozoobenthic assemblages in perennial springs in north-western Switzerland. Hydrobiologia 568:467-475. 